13

\title{
Термостабильные сегнетоэлектрические конденсаторы на основе градиентных пленок титаната бария-стронция
}

\author{
(C) А.В. Тумаркин, ${ }^{1,2}$ С.В. Разумов, ${ }^{1}$ В.А. Вольпяс, ${ }^{1}$ А.Г. Гагарин, ${ }^{1}$ \\ А.А. Одинец, ${ }^{1}$ М.В. Злыгостов, ${ }^{1}$ Е.Н. Сапего ${ }^{1}$ \\ ${ }^{1}$ Санкт-Петербургский государственный электротехнический университет „ЛЭТИ“, \\ 197376 Санкт-Петербург, Россия \\ ${ }^{2}$ Дагестанский государственный университет, \\ 367000 Махачкала, Россия \\ e-mail: twittine@list.ru
}

(Поступило в Редакцию 17 января 2017 г.)

Экспериментально исследовано влияние давления рабочего газа в процессе ионно-плазменного распыления на свойства осаждаемых сегнетоэлектрических покрытий титаната бария-стронция. Варьирование давления рабочего газа в процессе осаждения позволяет менять компонентный состав осаждаемого слоя, что приводит к размытию фазового перехода и улучшению температурной стабильности свойств сегнетоэлектрической пленки. Последовательность расположения слоев влияет на температуру максимума диэлектрической проницаемости, форму зависимости емкости от температуры и вольт-фарадные характеристики конденсаторных структур.

DOI: 10.21883/JTF.2017.10.45005.2168

\section{Введение}

В настоящее время существует устойчивый интерес к сегнетоэлектрическим (СЭ) материалам, обусловленный возможностью создания на их основе электрически управляемых сверхвысокочастотных (СВЧ) устройств [1-3]. Наиболее перспективными сегнетоэлектрическими материалами для СВЧ применений являются твердые растворы титанатов бария и стронция $\mathrm{Ba}_{x} \mathrm{Sr}_{1-x} \mathrm{TiO}_{3}$ (BST), электрофизические свойства которых изменяются в широких пределах [4]. Сегодня на базе BST тонких пленок реализованы лабораторные макеты управляемых СЭ конденсаторов с высокой добротностью [5] и фазовращателей для частотного диапазона вплоть до $60 \mathrm{GHz}[6,7]$.

Однако основным фактором, ограничивающим использование сегнетоэлектриков в технике СВЧ, является сильная зависимость свойств сегнетоэлектрического материала от температуры [8]. Очевидно, что исследования технологии получения сегнетоэлектрических пленок, направленные на минимизацию температурной зависимости их свойств, являются актуальной задачей.

В частности, перспективным методом повышения температурной стабильности свойств СЭ элементов является использование многослойных структур на основе пленок различного компонентного состава. Комбинация слоев с различными температурами фазового перехода „сегнетоэлектрик-параэлектрик“ приводит к размытию температурной зависимости эффективной диэлектрической проницаемости структуры. В обзоре [9] приводятся данные по температурному коэффициенту емкости (ТКС) трехслойных BST-элементов порядка $10^{-3} \mathrm{~K}^{-1}$ в диапазонах температур $(-10-20)^{\circ} \mathrm{C}$ и $(20-90)^{\circ} \mathrm{C}$. Наилучшие на сегодня результаты по температурной стабильности СЭ структур опубликованы в работе [10]:
ТКС двуслойных элементов на основе BST-пленок с содержанием Ва 50 и 90\% не превышает $10^{-4} \mathrm{~K}^{-1}$ в диапазоне температур $(-25-125)^{\circ} \mathrm{C}$, что сопоставимо с аналогичной величиной полупроводниковых элементов. Необходимо подчеркнуть, что свойства многослойной структуры зависят не только от состава слоев, но и от их толщины и положения в структуре [9-11].

Отметим, что сегодня независимо от метода получения пленок для формирования слоистых структур переменного компонентного состава в основном применяется последовательное осаждение слоев из нескольких источников (распыление мишеней различного компонентного состава, использование различных смесей прекурсоров и т.д.) [3,8,9]. Смена источников даже в едином технологическом цикле приводит к кратковременному прерыванию процесса осаждения и, как следствие, к образованию дефектного переходного слоя между осаждаемыми слоями. Как альтернатива такому подходу в настоящей работе исследуется возможность создания градиентных по составу пленок BST, используя ионно-плазменное распыление (ИПР) одного источника материала (мишени определенного состава) [12]. Такой подход дает возможность избежать формирования дефектных слоев, возникающих при смене источника, и реализовать структуру с непрерывным изменением компонентного состава по толщине за счет управления потоками осаждаемых компонентов в процессе роста пленки.

Осаждение пленочных покрытий методом ИПР можно условно разделить на два этапа. Первый этап, состоящий из распыления мишени и транспорта частиц через газовую среду, определяет характеристики потока частиц, достигших подложки. Компонентный состав распыляемой мишени, давление и состав рабочего газа, расстояние между катодом и подложкой - основные факторы, 
Характеристики полученных образцов

\begin{tabular}{c|c|c|c|c|c|c|c}
\hline $\begin{array}{c}\text { № } \\
\text { образца }\end{array}$ & $\begin{array}{c}\text { Давление } \\
\text { газа, Рa }\end{array}$ & $\begin{array}{c}\text { Толщина } \\
\text { пленки, } \mathrm{nm}\end{array}$ & $\begin{array}{c}\text { Состав пленки } \\
\text { (по ХRD) }\end{array}$ & $T_{\max }, \mathrm{K}$ & $\begin{array}{c}\text { ТКС } \cdot 10^{4} \mathrm{~K}^{-1} \\
160-220 \mathrm{~K}\end{array}$ & $\begin{array}{c}Q(0 \mathrm{~V}) \\
2 \mathrm{GHz}\end{array}$ \\
\hline 1812 & 2 & 150 & $\mathrm{Ba}_{0.3} \mathrm{Sr}_{0.7} \mathrm{TiO}_{3}$ & 170 & 22 & 2 & 45 \\
1814 & 60 & 150 & $\mathrm{Ba}_{0.45} \mathrm{Sr}_{0.65} \mathrm{TiO}_{3}$ & 210 & 26 & 1.9 & 46 \\
1862 & 2 & 100 & - & 190 & 1.5 & 2.4 & 50 \\
1861 & 60 & 50 & - & 170 & 18 & 1.7 & 30
\end{tabular}

определяющие вид энергетического спектра распыленных атомов, процесс их переноса в пространстве дрейфа „мишень-подложка“, энергетические и угловые распределения атомов, осаждающихся на подложку.

Второй этап - это процессы, происходящие на поверхности подложки, определяемые в первую очередь ее температурой $[13,14]$.

Целью настоящей работы является исследование возможностей управления потоками компонентов, приходящих на подложку в процессе роста слоев с целью получения градиентных по составу BST-пленок, исследование структурных свойств пленок в зависимости от давления рабочего газа в процессе осаждения и исследование электрофизических свойств градиентных сегнетоэлектрических BST-структур.

\section{Эксперимент}

В настоящей работе исследовались пленки BST, полученные методом ВЧ магнетронного распыления керамической мишени $\mathrm{Ba}_{0.4} \mathrm{Sr}_{0.6} \mathrm{TiO}_{3}$ диаметром $76 \mathrm{~mm}$. Выбор состава распыляемой мишени и технологических режимов осаждения пленок сделан на основе результатов предыдущих исследований, позволивших определить область технологических параметров для получения пленок BST с электрофизическими характеристиками, достаточными для СВЧ применений [5]. Расстояние мишень-подложка составляло $2.5 \mathrm{~cm}$. Перед процессом осаждения проводилось предраспыление мишени в стороне от подложкодержателя в течение $30 \mathrm{~min} \mathrm{c}$ целью очистки поверхности. Осаждение проводилось на подложки чистого сапфира ( $r$-срез) и сапфира с платиновым подслоем при температуре $T_{s}=800^{\circ} \mathrm{C}$. Контроль температуры осуществлялся с помощью термопары, размещенной под подложкодержателем. В качестве рабочего газа использовался кислород. Мощность разряда составляла $100-180 \mathrm{~W}$, давление рабочего газа изменялось в интервале от 2 до $60 \mathrm{~Pa}$. После осаждения пленки охлаждались в атмосфере чистого кислорода со скоростью $2-3^{\circ} \mathrm{C} / \mathrm{min}$.

Градиентные по составу СЭ структуры были получены распылением мишени $\mathrm{Ba}_{0.4} \mathrm{Sr}_{0.6} \mathrm{TiO}_{3}$ при различном давлении кислорода. В первой серии экспериментов начальный слой толщиной $100 \mathrm{~nm}$ осаждался при давлении $2 \mathrm{~Pa}$, затем давление увеличивалось до $60 \mathrm{~Pa}$ и происходило осаждение второго слоя толщиной $50 \mathrm{~nm}$. Во второй серии слои осаждались в обратной последовательности $(60 \mathrm{~Pa}-50 \mathrm{~nm}, 2 \mathrm{~Pa}-100 \mathrm{~nm})$. Технологические параметры и характеристики полученных пленок приведены в таблице.

Кристаллическая структура и фазовый состав полученных пленок исследовались методом рентгеновской дифракции (XRD) с помощью дифрактометра Rigaku-Dmax „Gagerflex“ (излучение $\mathrm{Cu} K_{\alpha}$ ). Компонентный состав оценивался методом рассеяния ионов средних энергий (РИСЭ). Морфология поверхности исследовалась методами атомно-силовой (АСМ) и электронной (ЭМ) микроскопии. Для электрофизических исследований на основе пленок BST были сформированы конденсаторные планарные структуры „BST-металл“ и плоскопараллельные структуры „металл-BST-металл“ (МДМ). Нижний электрод МДМ-структур толщиной $\sim 100 \mathrm{~nm}$ формировался посредством осаждения Рt-слоя магнетронным распылением с последующей литографией и ионным травлением. После осаждения СЭ пленки проводилась ее литография путем химического травления в смеси кислот $\mathrm{HF}-\mathrm{HNO}_{3}$. Верхние электроды планарных и МДМ-структур были изготовлены термическим осаждением $1 \mu \mathrm{m}$ пленки $\mathrm{Cu}$ с адгезионным подслоем $\mathrm{Cr}$, литографией и химическим травлением. Измерения СВЧ характеристик (емкость $C$ и добротность $Q$ ) конденсаторов были проведены резонансным методом на частоте $2 \mathrm{GHz}$. Управляемость конденсаторов рассчитывалась как отношение емкостей при нулевом и максимальном приложенных напряжениях управления $\left(n=C(0 V) / C\left(U_{\max }\right)\right)$.

\section{Результаты и обсуждение}

При осаждении пленок методом ИПР процесс переноса частиц от мишени к подложке определяется рядом следующих эффектов: образование направленного потока частиц, упругое рассеяние на атомах рабочего газа, термализация и диффузионное распространение распыленного потока. Под термализацией атомных частиц подразумевается потеря ими энергии при столкновениях с частицами газовой среды до состояния термодинамического равновесия с ней. Сопоставление длины термализации с расстоянием „мишень-подложка“ при 


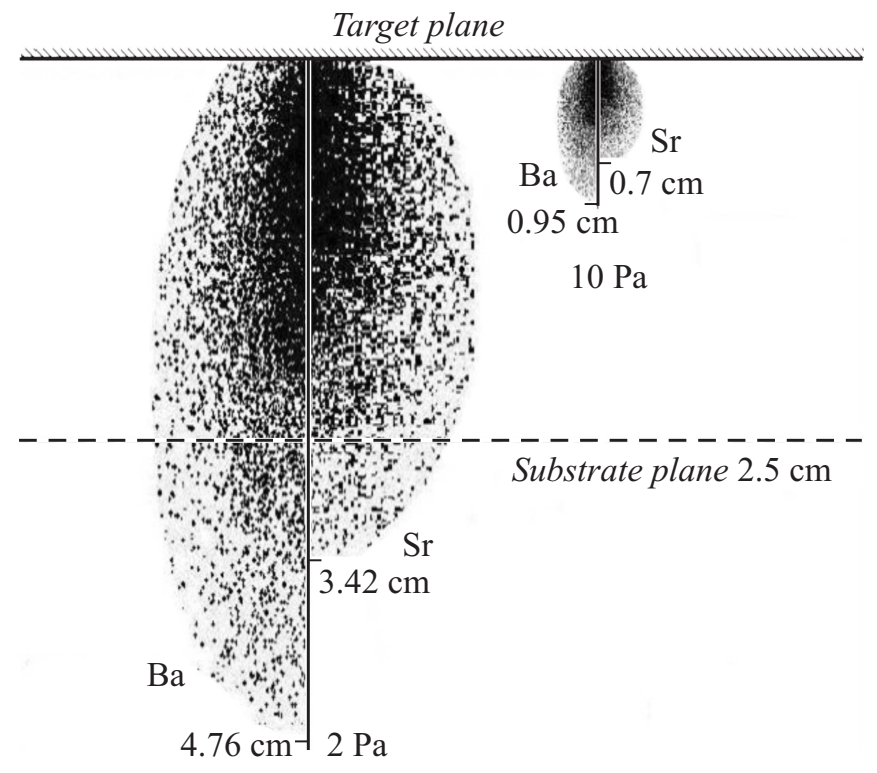

Pис. 1. Зона термализации атомов $\mathrm{Ba}$ и $\mathrm{Sr}$ в $\mathrm{O}_{2}$ при давлении рабочего газа 2 и $10 \mathrm{~Pa}$.

различных давлениях рабочего газа позволяет разделить направленный и диффузионный режимы осаждения пленок.

Длина термализации атомов напрямую влияет на соотношение потоков компонентов, приходящих на подложку, и ее изменение приводит к изменению компонентного состава растущей пленки по сравнению с распыляемой мишенью [15]. Так как длина зоны термализации определяется частотой столкновений распыленных частиц с атомами рабочего газа, то увеличение давления рабочего газа приводит к уменьшению длины термализации. Таким образом, при помощи изменения давления рабочего газа в процессе осаждения многокомпонентной пленки появляется возможность по-разному влиять на длину термализации атомов различных масс [12], плотность потока и скорость доставки распыленных атомов к подложке.

Статистическое моделирование процессов распыления BST-мишени и переноса распыленных атомов через газовую среду позволяет оценить энергетические характеристики и количественные соотношения компонентов, приходящих на подложку [15]. На рис. 1 представлены зоны термализации атомов $\mathrm{Ba}$ и $\mathrm{Sr}$ при различных давлениях рабочего газа - кислорода, оцененные в результате моделирования. Величина представленной границы зоны термализации распыленных атомов соответствует термализации 95\% их первоначального потока.

Согласно моделированию длина зоны термализации атомов $\mathrm{Ba}$ и $\mathrm{Sr}$ при давлении $2 \mathrm{~Pa}$ превышает расстояние мишень-подложка $2.5 \mathrm{~cm}$. Следовательно, на подложку они осаждаются как из прямого потока, так и в диффузионном режиме. Атомы бария как самые тяжелые дольше сохраняют прямолинейное направление движения и осаждаются преимущественно под зоной распыления. Таким образом, подложка, располагаемая в центре круговой зоны распыления, при низких давлениях рабочего газа оказывается обедненной барием и обогащенной стронцием. Далее мы будем рассматривать именно такое местоположение подложки.

При увеличении давления кислорода уже до $10 \mathrm{~Pa}$ за счет увеличения количества столкновений длина зоны термализации атомов $\mathrm{Ba}$ и $\mathrm{Sr}$ сокращается и становится существенно меньше, чем расстояние мишень-подложка, как показано на рис. 1 справа. В силу разницы в массах „виртуальный“ источник диффузионных атомов Ва находится ближе к подложке, чем у атомов $\mathrm{Sr}$. Поэтому при увеличении давления рабочего газа и по мере перехода в диффузионный режим плотность потока приходящих на подложку атомов Ва будет возрастать, и параметр стехиометрии , $x^{66}$ в пленке будет увеличиваться. Результаты моделирования показывают, что компонентный состав потока распыленных атомов, достигших подложки, составляет $x=0.32$ при давлении $2 \mathrm{~Pa}, x=0.42$ при давлении $20 \mathrm{~Pa}$ и $x=0.44$ при $60 \mathrm{~Pa}$. Отметим, что рост давления в диапазоне 20-60 Ра не приводит к сколько-нибудь значительному росту содержания Ва в пленке, так как при высоких давлениях термализация распыленных частиц происходит в непосредственной близости от мишени.

Для подтверждения результатов моделирования экспериментально исследовались пленки титаната бария-стронция, осажденные при различных давлениях кислорода на чистый $\mathrm{Al}_{2} \mathrm{O}_{3}$ и на сапфир с предварительно сформированными нижними Рt-электродами. На рис. 2 приведены сравнительные дифрактограммы BST-пленок, осажденных на сапфир при давлениях кислорода 2 и 60 Ра. Вертикальными линиями обозначены позиции рефлексов для объемного материала $\mathrm{Ba}_{0.4} \mathrm{Sr}_{0.6} \mathrm{TiO}_{3}$. Согласно данным XRD-анализа, пленка BST, осажденная при низком давлении, обладает поликристаллической структурой; увеличение давления приводит к появлению текстуры (111). Исходя из положений дифракционных максимумов, оценены параметры кристаллической решетки кубического перовскита: $a=0.394 \mathrm{~nm}$ и $a=0.3952 \mathrm{~nm}$ для пленок, полученных при 2 и $60 \mathrm{~Pa}$ соответственно. На дифрактограмме на-

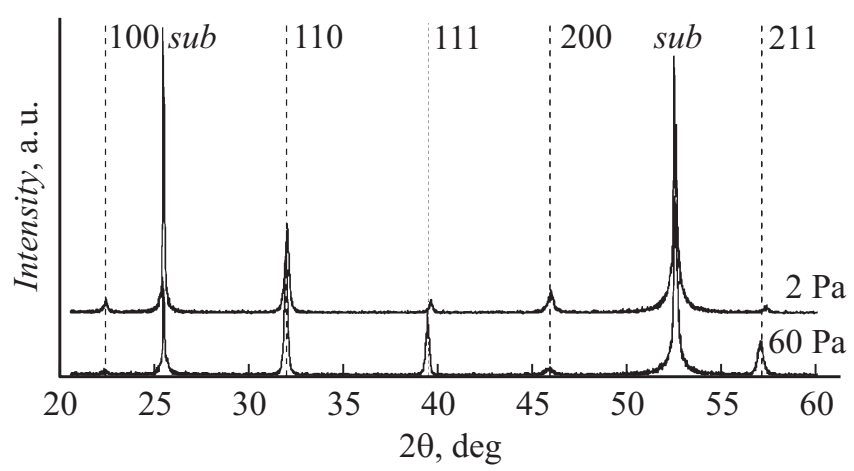

Рис. 2. Сравнительные дифрактограммы пленок титаната бария-стронция, полученных при различных давлениях кислорода. 

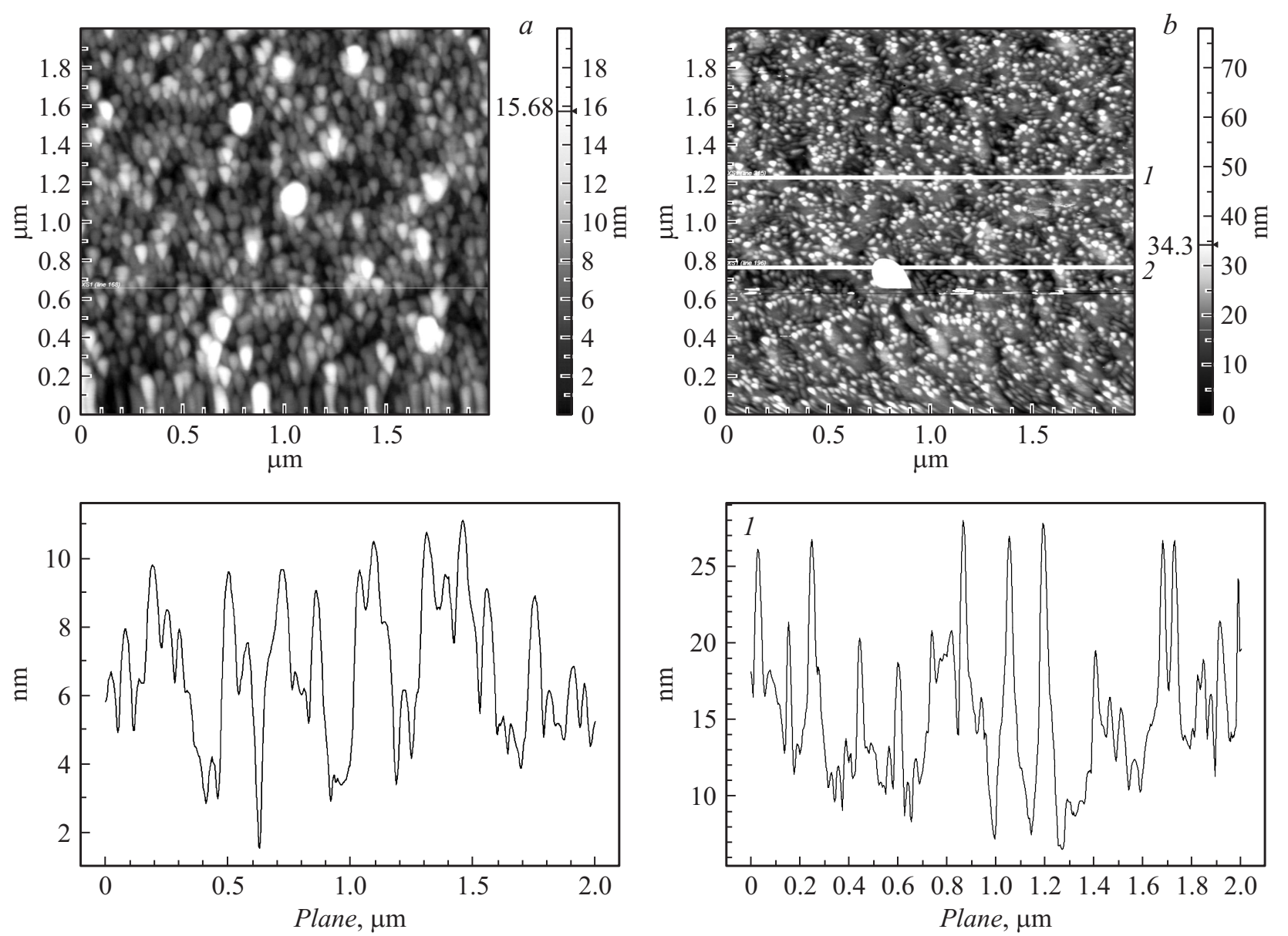

Рис. 3. АСМ-изображения поверхности пленок титаната бария-стронция, полученных при различных давлениях кислорода $(a-2 \mathrm{~Pa}, b-60 \mathrm{~Pa})$.

блюдается смещение рефлексов перовскита в сторону меньших углов при увеличении рабочего давления, что для поликристаллических пленок соответствует изменению компонентного состава [14] (35\% Ва при 2 Ра и $45 \% \mathrm{Ba}$ при $60 \mathrm{~Pa})$. Кристаллическая структура и состав BST-пленок на платиновом подслое повторяет вышеописанную тенденцию.

Результаты исследований компонентного состава BST-пленок на сапфире методом РИСЭ также свидетельствуют о зависимости соотношения $\mathrm{Ba}$ и $\mathrm{Sr}$ в пленках от давления кислорода. Согласно данным РИСЭ, пленки, осажденные при $2 \mathrm{~Pa}$, демонстрируют состав $\mathrm{Ba}_{0.3} \mathrm{Sr}_{0.7} \mathrm{TiO}_{3}$, тогда как пленки, полученные при $60 \mathrm{~Pa},-\mathrm{Ba}_{0.4} \mathrm{Sr}_{0.6} \mathrm{TiO}_{3}$.

Помимо компонентного состава, давление рабочего газа в процессе осаждения пленок методом ИПР оказывает сильное влияние на плотность потока компонентов, приходящих на подложку.

С.А. Кукушкиным и В.В. Слезовым в работе [16] показано, что в процессе роста пленки время жизни адатома и механизмы его движения по поверхности подложки сильно зависят от мощности источника, т.е. от количества частиц, достигающих подложки в единицу времени. Изменение плотности потока может привести к изменению механизма массопереноса адатомов и, таким образом, к смене механизма роста пленки.

В зависимости от плотности потока можно выделить сильные и слабые источники осаждаемого вещества [17], которым соответствуют высокие и низкие пересыщения соответственно. При сильных источниках скорость доставки атомов к подложке обычно больше или равна скорости роста пленки. В этом случае преобладающим механизмом массопереноса является поверхностная диффузия, а сформированная пленка состоит из мелких кристаллитов, имеющих практически одинаковый размер и фазовый состав. При слабых источниках пленка имеет достаточное количество времени, чтобы поглотить все приходящие атомы таким образом, что пересыщение будет падать. При этом массоперенос адатомов осуществляется диффузией через газовую фазу, а кристаллиты будут иметь сильный разброс по размерам [16].

На рис. 3 и 4 приведены изображения поверхности BST-пленок, полученные методами АСМ и ЭМ соответственно. Пленка, осажденная при $2 \mathrm{~Pa}$ (сильные источники), сформирована из примерно одинаковых кристаллитов, размером порядка $50 \mathrm{~nm}$, шероховатость поверхности составляет порядка $5 \mathrm{~nm}$ (рис. 3, $a$ ). Плен- 


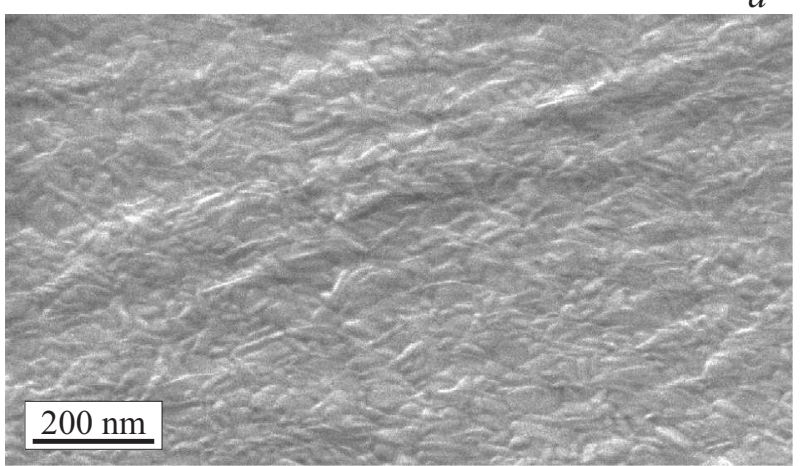

b

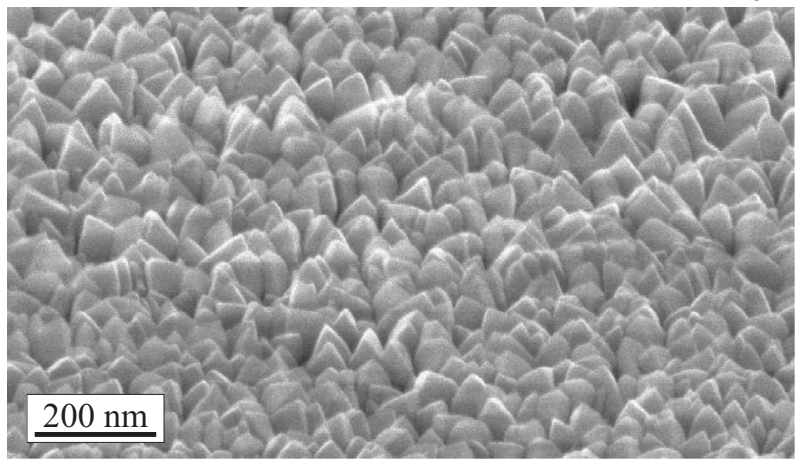

Рис. 4. ЭМ изображения поверхности пленок титаната бария-стронция, полученных при различных давлениях кислорода $(a-2 \mathrm{~Pa}, b-60 \mathrm{~Pa})$.

ка, полученная при давлении кислорода $60 \mathrm{~Pa}$ (слабые источники), состоит из кристаллитов с размерами $\sim 50-100 \mathrm{~nm}$ в плоскости подложки и рельефом порядка $15 \mathrm{~nm}$ (рис. 3, $b$ ). ЭМ изображения подтверждают данные XRD-анализа о формировании поликристаллической структуры BST-пленок при низком давлении кислорода (рис. 4,a) и появлении текстуры (111) при высоком (рис. 4, $b$ ).

Таким образом, согласно моделированию и экспериментальным данным, при осаждении BST-пленок методом ИПР увеличение давления кислорода приводит к обогащению пленки тяжелым компонентом (в нашем случае Ва) и, следовательно, к увеличению параметра кристаллической решетки $a$.

Хорошо известно, что параметр решетки твердого раствора титаната бария-стронция изменяется от 0.3905 до $0.40086 \mathrm{~nm}$ (при пересчете в псевдокубическую ячейку) при изменении параметра $x$ от $0\left(\mathrm{SrTiO}_{3}\right)$ до 1 $\left(\mathrm{BaTiO}_{3}\right)$ [18]. Следовательно, при изменении давления рабочего газа в процессе осаждения и создании направленных потоков одних компонентов на подложку и диффузионных потоков других появляется возможность получать покрытия с переменным параметром $x$ по толщине пленки, а значит, управлять температурной зависимостью свойств слоистой СЭ структуры.

На рис. 5 приведены температурные зависимости емкостей СЭ МДМ-конденсаторов $C(T)$, сформированных на основе пленок, осажденных при давле- нии 2 и $60 \mathrm{~Pa}$, а также температурные зависимости емкостей многослойных СЭ-конденсаторов, сформированных осаждением слоев различного состава (,2 Pa/60 Рa“ и „,60 Pa/2 Pa“). Температура максимума емкости, соответствующая температуре фазового перехода „сегнетоэлектрик-параэлектрик“, позволяет косвенно оценить состав твердого раствора титаната бария-стронция. Согласно [18], составам 35\% Ba/65\% Sr и $45 \% \mathrm{Ba} / 55 \% \mathrm{Sr}$ соответствуют температуры максимумов 170 и $210 \mathrm{~K}$. Положение максимумов с хорошей точностью подтверждает процентное содержание бария и стронция, оцененное рентгеноструктурным анализом, и положение об изменении компонентного состава твердого раствора в результате изменения давления рабочего газа.

Температуры фазовых переходов СЭ слоев с различным содержанием Ва можно рассматривать как границы диапазона, внутри которого возможна термостабилизация свойств многослойной емкостной структуры. Для оценки стабилизации емкости в многослойных конденсаторах может быть использована математическая модель, суть которой состоит в аппроксимации экспериментальной зависимости емкости $C$ от температуры $T$ по закону Кюри-Вейса, с учетом плотности емкости переходного слоя между электродом и СЭ пленкой. Переходной слой („мертвый слой“ ${ }^{\circ}$, обусловленный несоответствием структурных параметров СЭ пленки и электрода, физически может быть интерпретирован как слой, не обладающий сегнетоэлектрическими свойствами [19,20], а математически обеспечивает возможность определения величины расчетной емкости в точке перехода, а также размытие перехода в диапазоне температур.

Оценка плотности емкости переходного слоя производится путем экстраполяции к нулю зависимости емкости конденсатора от толщины СЭ пленки [21], что в нашем случае дает величину $27 \pm 10 \mathrm{fF} / \mu \mathrm{m}^{2}$.

Моделирование температурной зависимости емкости МДМ-конденсаторов на основе двуслойной СЭ пленки с $T_{C 1}=170 \mathrm{~K}(x=0.35)$ и $T_{C 2}=210 \mathrm{~K}(x=0.45)$ с

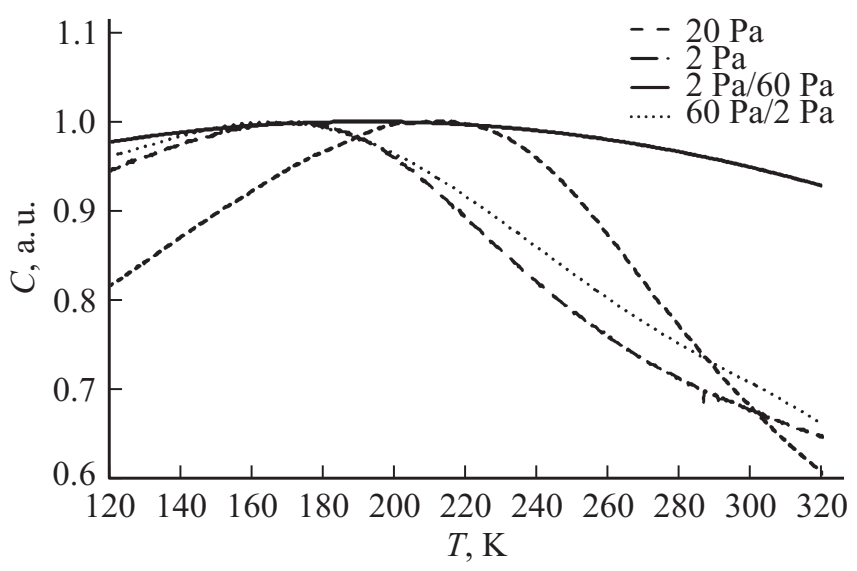

Рис. 5. Температурные зависимости емкости конденсаторов на основе пленок титаната бария-стронция, полученных при различных давлениях кислорода. 
учетом плотности емкости переходных слоев показало, что в рассматриваемом диапазоне температур может быть обеспечен ТКС, не превышающий $10^{-4} \mathrm{~K}^{-1}$, при условии, что толщины слоев связаны соотношением $d_{1}=2\left(C_{01} / C_{02}\right) d_{2}$, где $d_{1}$ и $d_{2}-$ толщины слоев, а $C_{01}$ и $C_{02}$ - постоянные Кюри-Вейса слоев с температурами максимума $T_{C 1}$ и $T_{C 2}$ соответственно [10].

Рассмотрим влияние последовательности расположения слоев, сформированных при различных давлениях рабочего газа на температурную зависимость емкости многослойного МДМ СЭ конденсатора.

Низкое давление кислорода на начальном этапе осаждения (2 Рa) позволяет сформировать BST-пленку с компонентным составом $0.35 \mathrm{Ba} / 0.65 \mathrm{Sr}$ с параметром $a=0.394 \mathrm{~nm}$, близким к размеру элементарной ячейки нижнего платинового слоя $(a=0.392 \mathrm{~nm})$. Дальнейшее увеличение давления до $60 \mathrm{~Pa}$ приводит к формированию слоя $\mathrm{c}$ высокой концентрацией $\mathrm{Ba}$ в твердом растворе $(0.45 \mathrm{Ba} / 0.55 \mathrm{Sr}, \quad a=0.3952 \mathrm{~nm})$. За счет комбинации слоев с различным компонентным составом происходит размытие фазового перехода „сегнетоэлектрик-параэлектрик“ и уменьшение температурной зависимости емкости по сравнению с пленками, осажденными при постоянном давлении кислорода (рис. 5, кривая „2 $\mathrm{Pa} / 60 \mathrm{~Pa}^{“ 6}$ ). ТКС многослойной структуры „2 $\mathrm{Pa} / 60 \mathrm{~Pa}^{“}$ в диапазоне температур $160-220 \mathrm{~K}$ составил $1.5 \cdot 10^{-4} \mathrm{~K}^{-1}$, что сопоставимо с аналогичной характеристикой полупроводниковых элементов.

Обратная комбинация слоев („60 Pa/2 Pa“) не приводит к сколько-нибудь существенному размытию фазового перехода, так как осаждение BST-слоя при высоком давлении рабочего газа приводит к обогащению пленки тяжелым компонентом, что увеличивает размер элементарной ячейки. Таким образом, увеличивается рассогласование решеток растущей пленки и нижнего платинового электрода. Это приводит к образованию дефектного слоя с низкой диэлектрической проницаемостью на границе раздела Pt/BST и к эффективному уменьшению толщины СЭ слоя, осаждаемого при давлении $60 \mathrm{~Pa}$. Если принять во внимание, что уменьшение толщины СЭ слоя увеличивает его емкость в слоистой структуре, то при последовательном включении слоев в общую емкость плоскопараллельного конденсатора увеличение емкости слоя приводит к уменьшению его вклада в суммарную емкость. В этом случае основной вклад в емкость многослойной структуры „,60 Pa/2 Рa“ вносит СЭ слой, осажденный при давлении $2 \mathrm{~Pa}$, что хорошо видно на рис. 5 по положению максимума $C(T)$. Температурный коэффициент емкости такой структуры в исследуемом диапазоне температур составил $\sim 2 \cdot 10^{-3} \mathrm{~K}^{-1}$.

На рис. 6 приведены вольт-фарадные характеристики CЭ конденсаторов на основе BST-пленок, осажденных при различных давлениях рабочего газа. Образец, полученный в режиме с повышением давления кислорода в процессе осаждения, проявляет высокую нелинейность $n=2.5$, тогда как управляемость МДМ-элемента, сформированного при уменьшении давления в ходе роста

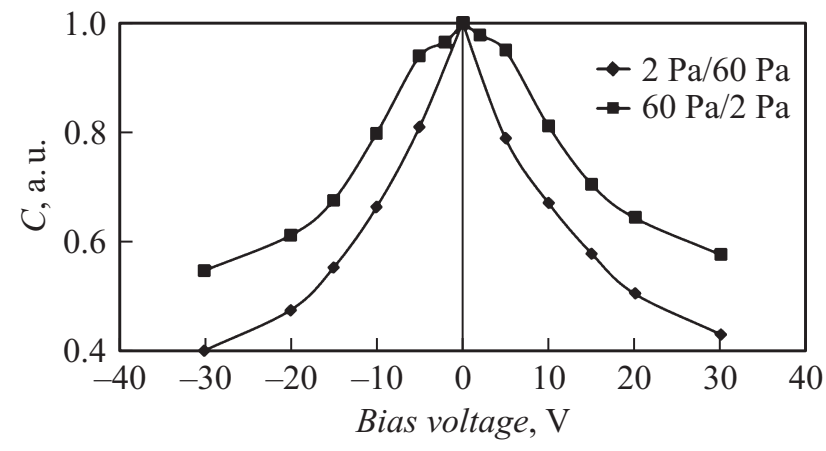

Рис. 6. Вольт-фарадные зависимости плоскопараллельных структур „Pt-CЭ-Cu“ на основе тонких сегнетоэлектрических слоев различного компонентного состава.

СЭ пленки, составляет $n=1.7$. Ухудшение нелинейности BST-пленки, осажденной при понижении давления, можно объяснить наличием „мертвого слоя“, не обладающего СЭ свойствами, на границе раздела „платина-BST“ из-за большего, чем в первом случае, рассогласования решеток. Этот слой с низкой диэлектрической проницаемостью, включенный последовательно с СЭ слоем, уменьшает нелинейность конденсаторной структуры в целом. Таким образом, последовательность расположения слоев разного состава влияет как на температуру максимума диэлектрической проницаемости и форму зависимости емкости от температуры, так и на вольт-фарадные характеристики емкостных структур.

\section{Выводы}

Исследовано влияние давления рабочего газа в процессе ионно-плазменного распыления на свойства осаждаемых сегнетоэлектрических покрытий. Показано, что давление рабочего газа влияет на длину термализации распыленных атомов. Сопоставление длины термализации с расстоянием „мишень-подложка“ при различных давлениях позволяет разделить направленный и диффузионный режимы осаждения пленок. Увеличение давления кислорода при осаждении многокомпонентных СЭ оксидов методом ИПР приводит к обогащению пленки тяжелым компонентом и, следовательно, к увеличению параметра кристаллической решетки.

Согласно экспериментальным данным, варьирование давления в процессе формирования BST-пленок методом ИПР позволяет менять компонентный состав осаждаемой пленки в пределах $15 \%$ (в нашем случае от 30 до 45\% содержания Ва). Изменение температурного диапазона, в котором возможна термостабилизация свойств многослойной структуры, может быть достигнуто соответствующим выбором компонентного состава распыляемой мишени.

Предложен метод получения градиентных по компонентному составу слоев за счет управления потоком компонентов, приходящих на подложку, при использо- 
вании одной керамической мишени. Изменение компонентного состава слоев достигается путем изменения давления кислорода в ходе осаждения пленки. В случае формирования многослойных МДМ-структур, осаждение СЭ BST-пленки на платиновый подслой при пониженном давлении рабочего газа минимизирует толщину переходного слоя между нижним электродом и пленкой за счет обеднения СЭ пленки барием и согласования кристаллических решеток слоев. Дальнейшее увеличение давления приводит к формированию слоя с высокой концентрацией Ва в твердом растворе. Комбинация слоев с различным компонентным составом позволяет уменьшить температурный коэффициент емкости сегнетоэлектрических конденсаторов более чем на порядок по сравнению с элементами, сформированными при постоянном давлении кислорода.

Авторы выражают благодарность С.В. Сенкевичу за исследование пленок методом АСМ.

Исследование выполнено при частичной финансовой поддержке РФФИ в рамках научных проектов № 16-07-00617, 16-08-00808, 16-29-05147; теоретическая часть работы, включающая статистическое моделирование, выполнена за счет гранта Российского научного фонда в рамках проекта № 15-19-10049.

\section{Список литературы}

[1] Aftab A., Irene A.G., Amir K.K. // Appl. Phys. Rev. 2015. Vol. 2. P. 011302.

[2] Gevorgian S. Ferroelectrics in microwave devices, circuits and systems. London: Springer, 2009. 396 p.

[3] Рабе К.М., Ана Ч.Г., Трискона Ж.М. Физика сегнетоэлектриков. Современный взгляд. М., БИНОМ. Лаборатория знаний, 2011. $440 \mathrm{c}$.

[4] Barranco A.P. Advances in Ferroelectrics. Havana: InTech, 2012. 532 p.

[5] Тумаркин А.В., Тепина Е.Р., Ненашева Е.А., Картенко Н.Ф., Козырев А.Б. // ЖТФ. 2012. Т. 82. Вып. 53. С. 5357.

[6] Козырев А.Б., Гайдуков М.М., Гагарин А.Г., Тумаркин А.В., Разумов С.В. // Письма в ЖТФ. 2002. Т. 28. Вып. 6. С. 5156.

[7] Kozyrev A., Ivanov A., Soldatenkov O., Tumarkin A., Ivanova S., Kaydanova T., Perkins J.D., Alleman J., Ginley D.S., Sengupta L., Chiu L., Zhang X. // Integr. Ferroelectr. 2003. Vol. 55. P. 847-852.

[8] Mantese V., Aplay S.P. Graded ferroelectrics, transpacitors and transponents. N. Y.: Springer, 2005. $153 \mathrm{p}$.

[9] Cole M.W. // Ferroelectrics. 2014. Vol. 470. P. 67-89.

[10] Гайдуков М.М., Тумаркин А.В., Гагарин А.Г., Козырев А.Б. // Письма в ЖТФ. 2014. Т. 40. Вып. 8. С. 37-43.

[11] Sigman J., Clem P.G., Nordquist C.D. // J. Appl. Phys. 2007. Vol. 102. P. 054106.

[12] Вольпяс В.А., Тумаркин А.В., Михайлов А.К., Козырев А.Б. // Письма в ЖТФ. 2016. Т. 42. Вып. 14. С. 87.

[13] Тумаркин А.В., Серенков И.Т., Сахаров В.И., Абросимов В.В., Одинеи, А.А. // ФТТ. 2016. Т. 58. Вып. 2. С. 354 359.
[14] Тумаркин А.В., Альмямев В.И., Разумов С.В., Гайдуков М.М. // ФТТ. 2015. Т. 57. Вып. 3. С. 540-544.

[15] Вольпяс В.А., Козырев А.Б. // ЖЭТФ. 2011. Т. 140. Вып. 1 (7). С. 196-204.

[16] Кукушкин С.A., Слезов В.В. Дисперсные системы на поверхности твердых тел. Механизмы образования тонких пленок (эволюционный подход). СПб.: Наука, 1996. 304 с.

[17] Kukushkin S.A. // Thin Solid Films. 1992. Vol. 207. P. 302 312.

[18] Вендик О.Г. Сегнетоэлектрики в технике СВЧ. М.: Сов. радио, 1979. $272 \mathrm{c}$.

[19] Pálová L., Chandra P., Rabe K.M. // Phys. Rev. 2007. Vol. 76. P. 014112.

[20] Pertsev N.A., Dittmann R., Plonka R., Wase R. // J. Appl. Phys. 2007. Vol. 101. P. 074102.

[21] Samoilova T., Gaidukov M., Tumarkin A., Gagarin A., Altynnikov A., Kozyrev A. // J. Appl. Phys. 2014. Vol. 115. P. 204103. 